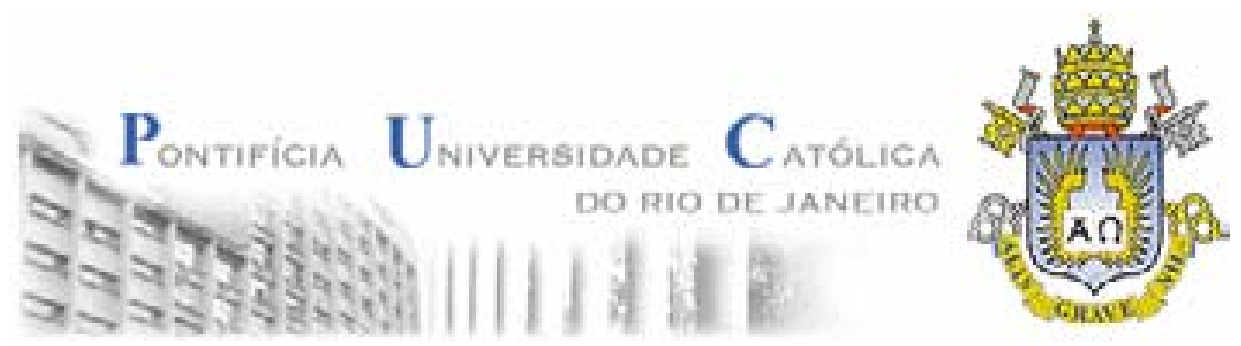

Ana Paula Barbosa Sobral

\title{
PREVISÃO DE CARGA HORÁRIA - UMA NOVA ABORDAGEM POR ÁRVORE DE DECISÃO
}

\section{Tese de Doutorado}

Tese apresentada como requisito parcial para obtenção do grau de Doutor pelo Programa de Pósgraduação em Engenharia Elétrica do Departamento de Engenharia Elétrica.

Orientador: Reinaldo Castro Souza

Volume I

Rio de Janeiro

Abril de 2003 
Ficha Catalográfica

Sobral, Ana Paula Barbosa

Previsão de carga horária - uma nova abordagem por árvore de decisão / Ana Paula

Barbosa Sobral; orientador: Reinaldo Castro

Souza. - Rio de Janeiro, Departamento de

Engenharia Elétrica, 2003.

[12], 56 f. : il. ; $30 \mathrm{~cm}$

Tese (doutorado) - Pontifícia Universidade Católica do Rio de Janeiro, Departamento de Engenharia Elétrica.

Inclui referências bibliográficas.

1. Engenharia elétrica - Teses. 2. Carga. 3. Previsão. 3. Curto prazo. 4. Árvore de decisão. 5. Redes neurais. 6. Temperatura. 7. Modelo híbrido. 8. Séries temporais. I. Souza, Reinaldo Castro. II. Pontifícia Universidade Católica do Rio de Janeiro. Departamento de Engenharia Elétrica. III. Título.

CDD: 621.3 


\section{Ana Paula Barbosa Sobral}

\section{Previsão de Carga Horária - Uma Nova Abordagem por Árvore de Decisão}

Tese de Doutorado apresentada como requisito parcial para obtenção do grau de Doutor pelo Programa de PósGraduação em Engenharia Elétrica do Departamento de Engenharia Elétrica do Centro Técnico Científico da PUC-Rio. Aprovada pela Comissão Examinadora abaixo assinada.

Dr. Reinaldo Castro Souza

Orientador

Departamento de Engenharia Elétrica - PUC-Rio

Dr. Plutarcho Maravilha Lourenço

CEPEL

Dr. João Carlos de Oliveira Aires

LIGHT

Dra. Monica Barros

Departamento de Engenharia Elétrica - PUC-Rio

Dr. Flávio Joaquim de Souza

UERJ

Dr. Gutemberg Hespanha Brasil

UFES

Prof. Ney Augusto Dumont Coordenador Setorial do Centro

Técnico Científico - PUC-Rio

Rio de Janeiro, 29 de abril de 2003 
Este trabalho é dedicado aos meus pais, Vera e Jorge, que sempre torceram pela filhona. 


\section{AGRADECIMENTOS}

- Ao maior mestre de todos, DEUS, pois de alguma forma vive nos ensinando o milagre da vida;

- Ao meu professor e orientador Reinaldo que acreditou no meu potencial;

- Ao meu orientador do exterior, Louis Wehenkel, que me aceitou como pesquisadora visitante e me proporcionou uma experiência acadêmica ímpar;

- Ao amigo Aboud que foi um grande mestre durante meu período de pesquisa no Setor Elétrico;

- A minha amiga e companheira de "morada", Lilica, que hoje é mais que uma irmã;

- Aos meus amigos: Helio, Lucio, Elma, Zé Américo, Pedreira, Tomas, Marcia (DEE) e Zanini pelos "puxões de orelha" nas horas certas e pelas palavras de carinho nos meus momentos difíceis;

- As minhas professoras de língua estrangeira, Edna Pacheco (Inglês) e Tereza Moreira (Francês), que foram capazes de despertar meu interesse e fascínio por uma área completamente diferente da minha;

- Aos meus sobrinhos, Woyron, Quito e Patrick, que ensinam a "Tia" ser criança;

- Marie Berthe (Université de Liège), Alcina (DEE), Ana Pascal (DEE) e Ana Paiva que sempre me ajudaram a apagar os "incêndios burocráticos";

- Aos "meninos" do suporte computacional, Luis Fernando, Evandro e Isnarde, pela paciência;

- Ao Arpoador, por me oferecer um "Cantinho Mágico" com direito: a banho de mar, céu azul, gente bonita, água de coco e um pôr do sol único no mundo;

- A "velha" Europa por ser um grande museu a céu aberto permitindo que a "neguinha da Ilha do Governador" descobrisse um "novo" mundo;

- Ao amigo Alexandre que, em algum lugar do universo, torceu muito por $\operatorname{mim}$;

- Ao CNPq pelo apoio financeiro no Brasil e no exterior. 


\section{RESUMO}

A importância da previsão de carga a curto prazo (até uma semana à frente) tem crescido recentemente. Com os processos de privatização e implantação de competição no setor elétrico brasileiro, a previsão de tarifas de energia vai se tornar extremamente importante. As previsões das cargas elétricas são fundamentais para alimentar as ferramentas analíticas utilizadas na sinalização das tarifas. Em conseqüência destas mudanças estruturais no setor, a variabilidade e a não-estacionaridade das cargas elétricas tendem a aumentar devido à dinâmica dos preços da energia. Em função das mudanças estruturais do setor elétrico, previsores mais autônomos são necessários para o novo cenário que se aproxima.

As ferramentas disponíveis no mercado internacional para previsão de carga elétrica requerem uma quantidade significativa de informações on-line, principalmente no que se refere a dados meteorológicos. Como a realidade brasileira ainda não permite o acesso a essas informações será proposto um previsor de carga para o curto-prazo, considerando restrições na aquisição dos dados de temperatura.

Logo, tem-se como proposta um modelo de previsão de carga horária de curto prazo (um dia a frente) empregando dados de carga elétrica e dados meteorológicos (temperatura) através de modelos de árvore de decisão. Decidiu-se pelo modelo de árvore de decisão, pois este modelo além de apresentar uma grande facilidade de interpretação dos resultados, apresenta pouquíssima ênfase em sua utilização na área de previsão de carga elétrica.

\section{Palavras-Chave:}

carga, previsão, curto prazo, árvore de decisão, redes neurais, temperatura, modelo híbrido, séries temporais. 


\section{ABSTRACT}

The importance of load forecasting for the short term (up to one-week ahead) has been steadily growing in the last years. Load forecasts are the basis for the forecasting of energy prices, and the privatisation, and the introduction of competitiveness in the Brazilian electricity sector, have turned price forecasting into an extremely important task.

As a consequence of structural changes in the electricity sector, the variability and the non-stationarity of the electrical loads have tended to increase, because of the dynamics of the energy prices. As a consequence of these structural changes, new forecasting methods are needed to meet the new scenarios.

The tools that are available for load forecasting in the international market require a large amount of online information, specially information about weather data. Since this information is not yet readily available in Brazil, this thesis proposes a short-term load forecaster that takes into consideration the restrictions in the acquisition of temperature data.

A short-term (one-day ahead) forecaster of hourly loads is proposed that combines load data and weather data (temperature), by means of decision tree models. Decision trees were chosen because those models, despite being easy to interpret, have been very rarely used for load forecasting.

\section{Keywords:}

load, forecasting, short-term, decision tree, neural networks, temperature, hybrid model, time series. 


\section{SUMÁRIO}

1. Introdução 13

1.1. Principais Contribuições 14

1.2. Definições 15

$\begin{array}{ll}\text { 1.3. Organização da Tese } & 15\end{array}$

2. Revisão Bibliográfica $\quad 17$

2.1. Modelos de Previsão de Carga Elétrica 17

2.2. Árvore de Regressão 19

3. Árvore de Decisão 21

3.1. Crescimento e Poda 25

3.2. CART 26

4. Modelagem Proposta 28

4.1. Etapa I: Classificação do Perfil em PU 30

4.2. Etapa II: Discriminação do Perfil em PU 30

4.3. Etapa III: Previsão da Demanda Média 32

5. Aplicação da Modelagem Proposta 40

5.1. Classificação do Perfil em PU 41

5.2. Discriminação do Perfil em PU do Dia Previsto 44

5.3. Previsão da demanda Média 51

5.4. Previsão da Carga Horária 54

5.5. Comparação dos Resultados 56

6. Conclusões $\quad 59$

$\begin{array}{ll}\text { 6.1. Trabalhos Futuros } & 60\end{array}$

7. Referências Bibliográficas 62 
8. Anexos

ANEXO I - LIGHT Serviços de Eletricidade S.A.

ANEXO II - Por que ordenar a matriz de dados por variável decisória em ordem ascendente e ordem descendente?

ANEXO III - Redes Neurais

ANEXO IV - Cálculo de Regressão por Mínimos Quadrados Recursivos 


\section{Lista de Tabelas}

Tabela 1 - Descrição das Etapas da Modelagem Proposta 29

Tabela 2 - Grupos de Curva de Carga 41

Tabela 3 - Regras da Árvore de Decisão 1

Tabela 4 - Regras da Árvore de Decisão $2 \quad 47$

Tabela 5 - Regras da Árvore de Decisão 348

Tabela 6 - Regras da Árvore de Decisão 4

Tabela 7 - Percentual de Acerto em cada Árvore de Decisão 50

Tabela 8 - MAPE de cada grupo 54

Tabela 9 - MAPE horário por modelo de previsão de carga para 199857

Tabela 10 - Ordenação ascendente de $x_{k} \quad 80$

Tabela 11 - Ordenação ascendente e descendente de $x_{k}$ 


\section{Lista de Figuras}

Figura 1 - Árvore de Decisão Binária $\quad 22$

Figura 2 - Árvore de Classificação 23

Figura 3 - Esquema da Modelagem Proposta 29

Figura 4 - Fluxograma da árvore de regressão TS-TARX 39

Figura 5 - Grupos de Perfis Típicos 43

Figura 6 - Árvore de Decisão para Final de Semana 46

Figura 7 - Árvore de Decisão de Verão e Inverno para Dias Úteis $\quad 47$

Figura 8 - Árvore de Decisão para Dia Útil de Verão 48

Figura 9 - Árvore de Decisão para Dia Útil de Inverno 49

Figura 10 - Função de Autocorrelação do Erro 55

Figura 11 - Perfil em PU para o dia 08/04/1998 55

Figura 12 - Carga horária para o dia 08/04/1998 56

Figura 13 - Comparação do MAPE dos 3 modelos 58

Figura 14 - Área de concessão da Light e Balanço Energético $\quad 74$

Figura 15 - Carga Média Diária $\quad 75$

Figura 16 - Perfis da Curva de Carga $\quad 76$

Figura 17 - Freqüência dos Horários de Ponta ao Longo dos Meses 77

Figura 18 - Evolução das cargas ao Longo dos Anos 79

Figura 19 - Rede "Feedforward" (Propagação Direta) 84

Figura 20 - Arquitetura de um Mapa Auto-Organizável vista no plano 87 
"Nasceste no lar que precisavas, vestiste o corpo físico que merecias, moras onde melhor Deus te proporcionou, de acordo com teu adiantamento. Possuis os recursos financeiros coerentes com as tuas necessidades, nem mais, nem menos, mas o justo para as tuas lutas terrenas. Teu ambiente de trabalho é o que elegeste espontaneamente para a tua realização. Teus parentes e amigos são as almas que atraístes, com tua própria afinidade. Portanto, teu destino está constantemente sob teu controle. Tu escolhes, recolhes, eleges, atrais, buscas, expulsas, modificas tudo aquilo que te rodeia a existência. Teus pensamentos e vontades são a chave de teus atos e atitudes... são as fontes de atração e repulsão na tua jornada - vivência. Não reclames nem te faças de vítima. Antes de tudo, analisa e observa. A mudança está em tuas mãos. Reprograme tua meta, busque o bem e viverás melhor. Embora ninguém possa voltar atrás e fazer um novo começo, qualquer um pode começar agora e fazer um novo fim."

Chico Xavier 